\title{
Genetic CJD with a novel E200G mutation in the prion protein gene and comparison with E200K mutation cases
}

\author{
Mee-Ohk Kim ${ }^{1 \dagger}$, Ignazio Cali ${ }^{2,3 \dagger}$, Abby Oehler ${ }^{4}$, Jamie C Fong ${ }^{1}$, Katherine Wong ${ }^{1}$, Tricia See ${ }^{1}$, Jonathan S Katz ${ }^{5}$, \\ Pierluigi Gambetti ${ }^{2}$, Brianne M Bettcher ${ }^{1}$, Stephen J DeArmond ${ }^{4}$ and Michael D Geschwind ${ }^{1 *}$
}

\begin{abstract}
A novel point mutation resulting in a glutamate-to-glycine substitution in PRNP at codon 200, E200G with codon 129 MV polymorphism (cis valine) and type $2 \operatorname{PrP}^{S c}$ was identified in a patient with a prolonged disease course leading to pathology-proven Jakob-Creutzfeldt disease. Despite the same codon as the most common genetic form of human PRNP mutation, E200K, this novel mutation (E200G) presented with a different clinical and pathological phenotype, including prolonged duration, large vacuoles, no vacuolation in the hippocampus, severe neuronal loss in the thalamus, mild cerebellar involvement, and abundant punctate linear and curvilinear deposition of $\operatorname{PrP}^{\mathrm{Sc}}$ in synaptic boutons and axonal terminals along the dendrites.
\end{abstract}

Keywords: Creutzfeldt-Jakob disease, E200K, familial CJD, Synaptic PrP ${ }^{\text {Sc }}$, Curvilinear PrP ${ }^{\text {Sc }}$

\section{Background}

Human prion diseases are unique in medicine as they occur as spontaneous, genetic and acquired forms. Sporadic Jakob-Creutzfeldt disease (sCJD) is the most common human prion disease, accounting for approximately $85-90 \%$ of cases, whereas autosomal dominant genetic forms, due to more than 30 mutations in the prion protein gene (PRNP), account for $10-15 \%$ of cases [1]. Glu200Lys (E200K) and Asp178Asn (D178N) are the most common PRNP mutations worldwide [2-8]. At least four founder groups of E200K are known with the two largest populations in the Middle East (Libyan Jews) and Slovakia [4,5,8-10]. We report a novel point mutation of PRNP at codon 200 resulting in a glutamate-to-glycine substitution, E200G, in a pathology-proven patient of British descent and compare findings to those of E200K cases.

\section{Case presentation}

A 59-year-old Caucasian woman with a reported 25-month history of motor and cognitive problems was referred to

\footnotetext{
* Correspondence: mgeschwind@memory.ucsf.edu

${ }^{\dagger}$ Equal contributors

'Department of Neurology, Memory and Aging Center, University of California, San Francisco (UCSF), San Francisco, CA 94143, USA Full list of author information is available at the end of the article
}

our clinical research center with suspected SCJD. Her first obvious symptoms began 25 months prior ("onset") with gradual onset of gait imbalance, fatigue and "loss of mental acuity," although there might have been very subtle changes in personality (irritability, decreased understanding and appreciation of humor, poor planning) even five months earlier. One month after onset, she developed difficulty walking. By four months, she could no longer correctly balance her checkbook and had worsened handwriting. At six months, language difficulties began, particularly noticeable during phone conversations. At seven months, she began missing freeway exits (reasons unclear). At 12 months, she developed a head tremor and at 17 months, nighttime leg cramps. By 18 months, all of the above symptoms had worsened, and she required a cane. At 20 months, she still was doing some, albeit more limited, driving, shopping, and light housework, with some fluctuation of her gait and memory abilities. By 22 months, she could no longer do these activities. At 25 months, when she first visited our center, she was wheelchair bound and had difficulty following conversations.

Her past medical history was unremarkable. Her father died at 50 from alcoholism and pneumonia, with presumed "alcohol-related dementia," which progressed rapidly during the last three months and "fast movements" during his 
last 6 weeks. The proband had an unaffected sibling, 11 years younger, and a half-sibling whose status is unknown (Figure 1).

At 25 months, she was alert and partially oriented, fluent, slightly hypophonic, but not dysarthric. She had mild anomia. Her MMSE was 26/30, missing points for floor, county and recall. More extensive neuropsychological testing revealed mild cognitive impairment across multiple domains, including visual memory and executive function (Table 1). Examination also was remarkable for jerky ocular pursuit (horizontal and vertical), increased latency with mild decreased velocity of horizontal saccades, extrapyramidal features (resting tremor in the face and bilateral upper extremities, action tremor in the bilateral upper extremities, mild cogwheel rigidity in the bilateral upper extremities, and bradykinesia greatest in the right arm and left leg), symmetric, distal, length-dependent, decreased pinprick and temperature in legs, asymmetric lower extremity reflexes (left side brisker), and cerebellar dysfunction (wide-based gait requiring assistance and truncal ataxia). There was no limb ataxia, myoclonus, dystonia, chorea, alien limb, or higher cortical sensory signs.

Her initial brain MRI at 17 months showed subtle cortical ribboning and striatal hyperintensity on FLAIR and DWI with restricted diffusion on ADC, which were more distinct and extensive by 25 months (Figure 2a-f). Her first EEG, at 25 months, showed bilateral slowing, predominant in the frontal and posterior regions, but no triphasic or epileptiform discharges. Extensive blood tests to rule out conditions other than CJD were negative. Basic CSF findings at 25 months were normal (RBC 1, WBC 1, protein 37, glucose 75, no oligoclonal bands, and IgG index of 0.5), except she had an elevated total tau of $1351 \mathrm{pg} / \mathrm{mL}$ ("> $1150 \mathrm{pg} / \mathrm{ml}$ consistent with
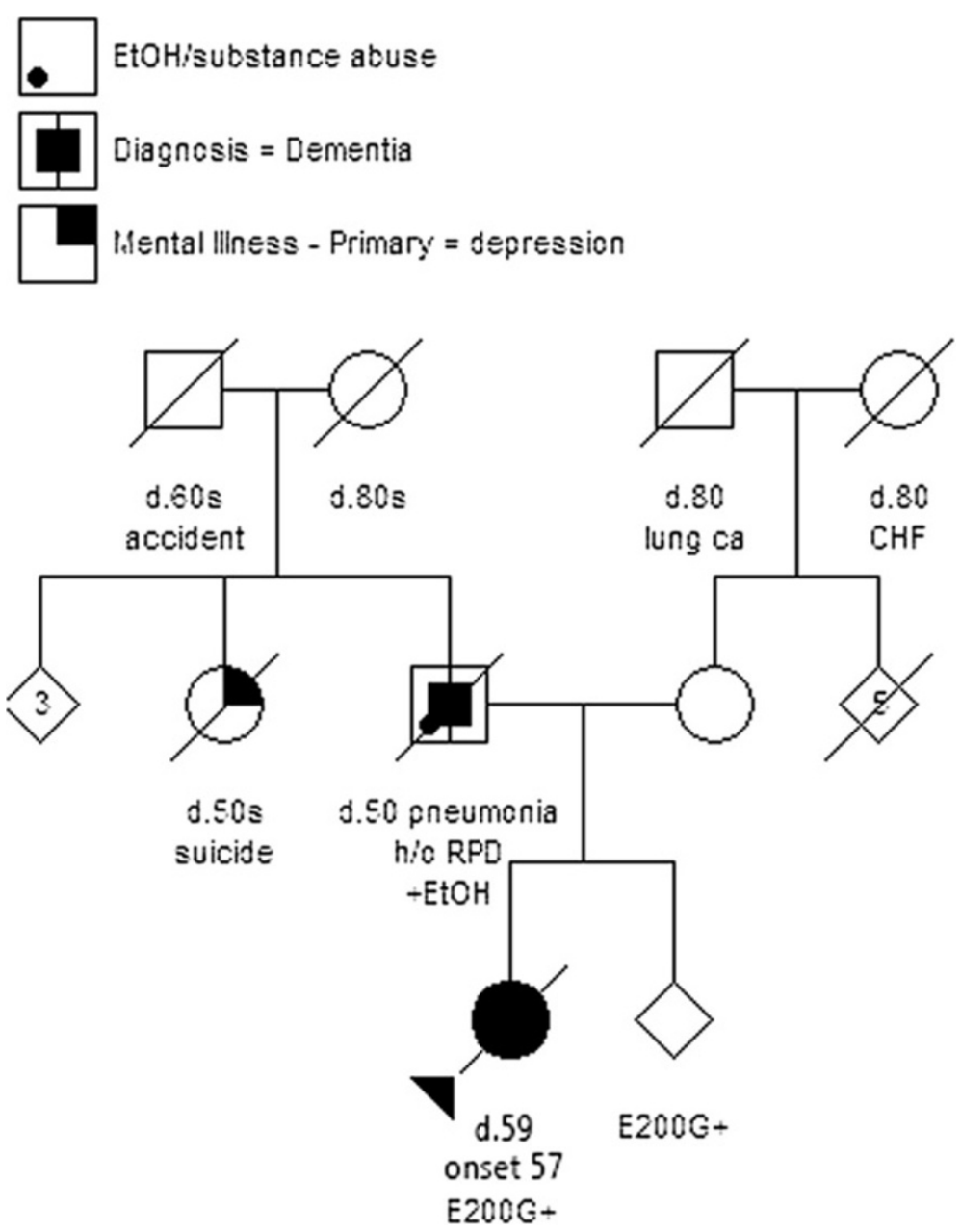

Figure 1 Family pedigree. Family pedigree of the proband of British descent with E200G mutation. Circles indicate females, and squares indicate males. Those whose gender is not disclosed are indicated with rhombi. A diagonal bar in the symbols indicate deceased. Arabic numerals " 3 " and " 5 " indicate the numbers of individuals. The proband with the E200G mutation (E200G+) is indicated by closed circle and arrowhead and her sibling with the same E200 mutation is also marked by "E200G+" (+EtOH = alcoholism, $\mathrm{d}$. = died at age, lung ca =lung cancer, $\mathrm{CHF}=$ congestive heart failure, $\mathrm{h} / \mathrm{o} \mathrm{RPD}=$ history of rapidly progressive dementia). 
Table 1 Serial longitudinal neuropsychological assessment of E200G case

\begin{tabular}{|c|c|c|c|}
\hline & Visit 1 & Visit 2 & Visit 3 \\
\hline & 25 months & 26 months & 28 months \\
\hline & Raw (Z-score) & Raw (Z-score) & Raw (Z-score) \\
\hline \multicolumn{4}{|l|}{ Global cognition } \\
\hline MMSE & $26^{1}$ & $24^{2}$ & 16 \\
\hline \multicolumn{4}{|l|}{ Memory } \\
\hline CVLT trial 5 & $4(-4.00)$ & $4(-4.00)$ & $0(-5.00)$ \\
\hline CVLT delay & $1(-4.00)$ & $1(-4.00)$ & $0(-4.00)$ \\
\hline CVLT recog hits & $15(0.00)$ & $15(0.00)$ & $13(-1.00)$ \\
\hline CVLT recog false pos & $3(-0.50)$ & $3(-0.50)$ & $16(-4.00)$ \\
\hline Benson figure delay recall & $3(-4.17)$ & $0(-5.48)$ & N/D \\
\hline Mean memory Z-score & -2.53 & -2.80 & -3.50 \\
\hline \multicolumn{4}{|l|}{ Executive function } \\
\hline Modified trails & $59^{\prime \prime}(-3.00)$ & 119" (-8.62) & $120 "(-8.71)$ \\
\hline Design fluency & $\mathrm{N} / \mathrm{A}$ & $5(-2.28)$ & $0(-4.07)$ \\
\hline Digit backwards span & $3(-1.85)$ & $3(-1.85)$ & $3(-1.85)$ \\
\hline Stroop inhibition & $31(-2.25)$ & $19(-3.50)$ & $\mathrm{N} / \mathrm{D}$ \\
\hline Mean executive Z-score & -2.37 & -4.06 & -4.88 \\
\hline \multicolumn{4}{|l|}{ Language } \\
\hline BNT-Abbrev & $13(-1.66)$ & $15(+0.55)$ & N/D \\
\hline \multicolumn{4}{|l|}{ Visuospatial } \\
\hline Benson figure copy & $13(-1.27)$ & $14(-1.36)$ & N/D \\
\hline
\end{tabular}

${ }^{1}$ Missed 2 points for orientation and 2 on recall. ${ }^{2}$ Missed 3 points for orientation and 3 on recall. Abbreviations and Definitions: MMSE Mini-Mental State Examination CVLT California Verbal Learning Test-II (16 word list), Recog Recognition, False Pos False Positive Total, Modified Trails Abbreviated trail-making task using numbers and days of the week, BNT-Abbrev Abbreviated (15-item) Boston Naming Test, N/D patient unable to perform, N/A not administered.

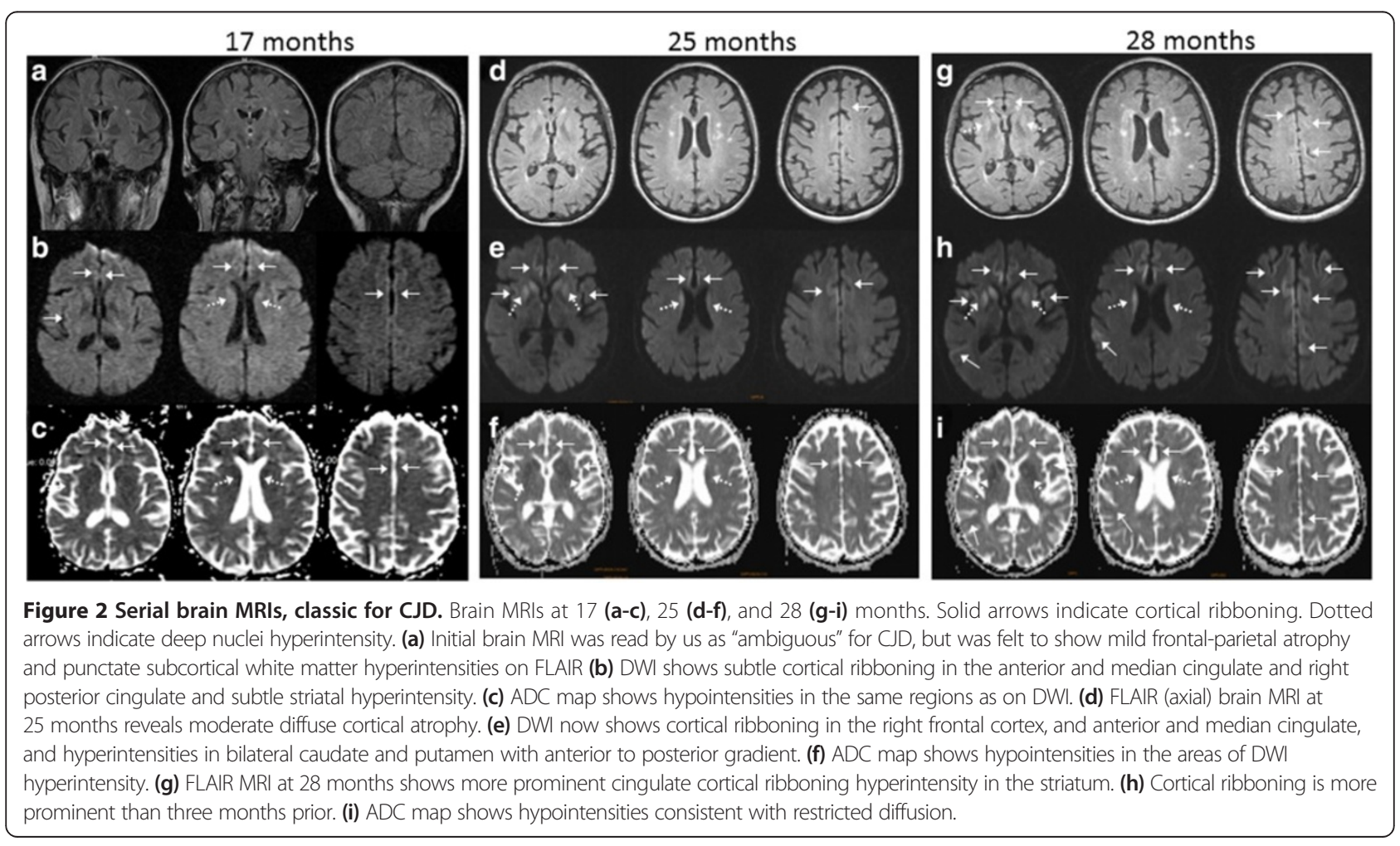


CJD," NPDPSC), ambiguous 14-3-3 protein (NPDPSC) and mildly elevated ("intermediate") neuron-specific enolase of $27 \mathrm{ng} / \mathrm{mL}$ (Mayo Laboratories; normal $<15$, intermediate $15-35,>35 \mathrm{ng} / \mathrm{ml}$ consistent with CJD). Follow-up neuropsychological testing one and three months later (at 26 and 28 months) showed further deterioration in memory and executive function (Table 1). Her brain MRI at 28 months showed profound cortical atrophy, brighter and more extensive DWI hyperintensities with increased restricted diffusion in these regions (Figure 2g-i). She passed away at 30 months, 5 months after diagnosis. Direct sequencing of the PRNP gene open reading frame, and subsequent cloning experiments (NPDPSC), from blood (and later from frozen brain tissue) revealed an E200G mutation with heterozygosity at codon 129 (MV; cis valine) in PRNP. Her younger asymptomatic full sibling carried the same mutation and codon 129 polymorphism.

Autopsy was performed one day after her passing. The brain weighed 1175 gm (normal 1100-1400 gm). Gross brain pathology showed atrophy in the frontal lobe, right greater than left, and loss of pigmented neurons in the substantia nigra. Microscopic examination revealed $\mathrm{PrP}^{\mathrm{Sc}}$ deposition characteristic of CJD, with both perivacuolar and diffuse finely granular synaptic staining in the cerebral cortex (Figure $3 \mathrm{a}$ ). Most $\mathrm{PrP}^{\mathrm{Sc}}$ consisted of finely granular deposits (2-4 $\mu \mathrm{m}$ diameter), which were distributed around and, occasionally, inside the neuronal perikarya and processes (Figure 3c). Occasional larger plaque-like deposits were also seen $(30-40 \mu \mathrm{m})$ (Figure 3a). In addition there were abundant punctate, linear and curvilinear arrays of $\mathrm{PrP}^{\mathrm{Sc}}$ in the striatum (Figures $3 \mathrm{~d}$ and 4 ) and other regions including Ammon's horn of the hippocampus, substantia nigra, midbrain tegmentum, periaqueductal gray, and medullary inferior olivary nucleus (Figure 4). MAP-2 immunostaining showed the linear and curvilinear arrays were associated with dendrites (Figure $3 \mathrm{i}$ ). $\operatorname{PrP}^{\mathrm{Sc}}$ was not co-localized with axonal markers including neurofilament $\mathrm{H}$ and phospho-neurofilament $\mathrm{H}$ (not shown). Some of the unusual linear and curvilinear $\operatorname{PrP}^{\mathrm{Sc}}$ deposits co-localized with or were adjacent to synaptophysin (presynaptic vesicle membrane protein) immunostaining, demonstrating the presence of $\mathrm{PrP}^{\mathrm{Sc}}$ in synaptic boutons and probably also in pre-synaptic axonal terminals (Figure $3 \mathbf{j}$ ).

In most regions of the cortex, vacuolation was in layers II-VI, more severely affecting layers III-VI (not shown), but in the insular cortex, it was confined to layers $\mathrm{V}$ and VI (Figure $3 \mathrm{~b}$ ). The mean diameter of gray matter vacuoles was $14.9 \mu \mathrm{m}$ (range 4-108 $\mu \mathrm{m}$ ), significantly larger than those observed in the NPDPSC E200K-129V (mean: $11.9 \mu \mathrm{m}$, range: $4-72 \mu \mathrm{m} ; \mathrm{P}<0.016$ ) and E200K129M (mean: $11.8 \mu \mathrm{m}$, range: $4-69 \mu \mathrm{m} ; \mathrm{P}<0.016$ ) cohorts. Vacuole size between the E200K-129V and -129M NPDPSC cohorts was not significantly different $(\mathrm{P}>0.016)$.
Reactive astrocytosis co-localized with vacuolation and $\mathrm{PrP}^{\mathrm{Sc}}$ deposition in all cortical regions and striatum, except in the insular cortex, where it was most intense in layers I-IV that contained sparse vacuolation and minimal $\operatorname{PrP}^{\mathrm{Sc}}$ (not shown).

The hippocampus did not exhibit vacuolation, or neuronal loss despite mild to severe $\operatorname{PrP}^{\mathrm{Sc}}$ deposits; furthermore astrocytosis was absent or moderately reactive (Figure 3e, f, Table 2). The thalamus showed overall mild vacuolation and mild to severe $\mathrm{PrP}^{\mathrm{Sc}}$ deposits, severe neuronal loss, and severe reactive astrocytosis, especially in the medial nuclei (Figure 3g, Table 2); in contrast, the thalami of the NPDPSC E200K-129M and -129V cases showed vacuoles but neither neuronal loss nor astrocytosis (Figure $3 \mathrm{~h}$ ). All brain regions were affected to a moderate or severe extent, except the cerebellum, which only had sparse $\operatorname{PrP}^{\mathrm{Sc}}$ staining, no vacuolation, and mild reactive astrocytosis in the cortex (not shown). In the cerebellar molecular layer, there were loose, round aggregates of fine granules, which occasionally were around cell bodies (not shown). Plaque-like $\operatorname{PrP}^{\mathrm{Sc}}$ deposits were observed in the granular cell layer, whereas perineuronal and intraneuronal staining patterns were predominant in the dentate nucleus, which also showed a moderate number of linear and curvilinear arrays (Figures $3 \mathrm{c}$ and 4). Table 2 shows lesion profiles of the E200G case.

Because other neurodegenerative proteins occasionally are found in sCJD and gPrD [11-15], we examined the status of hyperphosphorylated tau $(\mathrm{H \tau}), \beta$-amyloid $(\mathrm{A} \beta)$, $\alpha$-synuclein, TPD 43, and ubiquitin in our patient. The CP13 antibody specific for Ht was used to stain sections from the insula and putamen, the hippocampus and entorhinal cortex (EC), the inferior temporal lobe, and the midbrain with substantia nigra. Hт was found exclusively and focally in layers 3 and 4 of the EC (Figure 5a). Application of the 4G8 antibody for abnormal A $\beta$ neuritic and amyloid plaques in Alzheimer's disease (AD) did not reveal $A \beta$ plaques in our patient; many neuronal cell bodies, however, were $A \beta$ immunopositive in the entorhinal cortex layers 3 and 4 (Figure $5 \mathrm{~b}$ ). With the $\alpha$-synuclein antibody, no abnormal $\alpha$-synuclein in the form of classical Lewy bodies was found in the substantia nigra, as verified by the H\&E stain, or as cortical Lewy bodies (not shown). No displacement of TDP43 from the nucleus to the cytoplasm or neurites was identified in any brain regions examined (not shown). Ubiquitin and $\mathrm{PrP}^{\mathrm{Sc}}$ double immunofluorescence staining of the curvilinear $\mathrm{PrP}^{\mathrm{Sc}}$ deposits in the putamen and the cerebellar dentate nucleus did not show ubiquitin positive structures (not shown).

Western blot analysis of the proteinase $\mathrm{K}(\mathrm{PK})$-resistant $\operatorname{PrP}\left(\mathrm{PrP}^{\mathrm{Sc}}\right)$ from our patient showed $\mathrm{PrP}^{\mathrm{Sc}}$ with gel mobility of the unglycosylated $\operatorname{PrP}^{\mathrm{Sc}}$ isoform of $\sim 19 \mathrm{kDa}$, matching $\mathrm{PrP}^{\mathrm{Sc}}$ type 2 (Figure 6a). There was prominent 

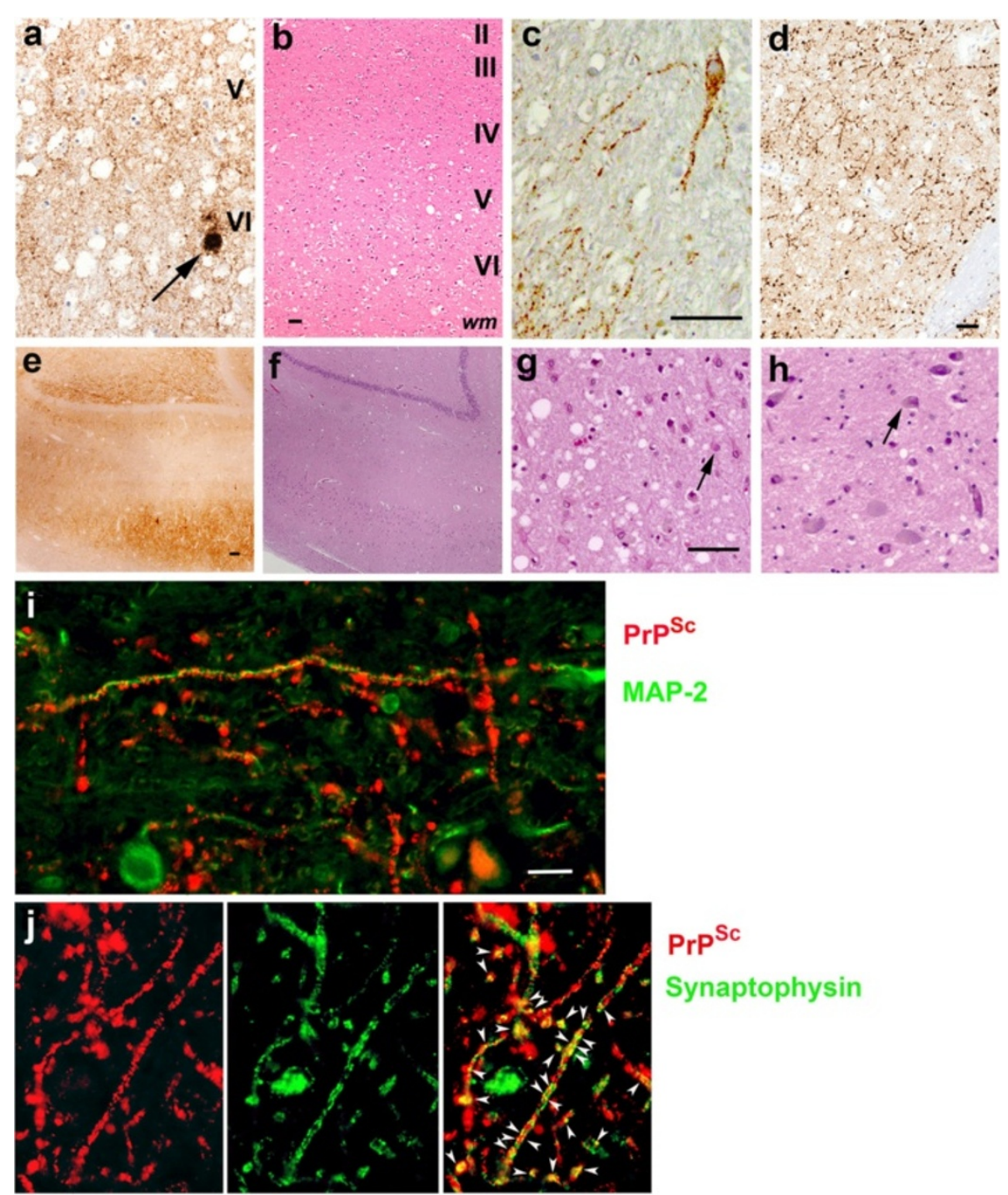

$\operatorname{PrP}{ }^{\mathrm{Sc}}$

Synaptophysin

Figure 3 Neuropathological immunohistochemistry of the E200G and a representative E200K case for comparison. (a-g E200G; h E200K) (a-b) insular cortex, (c) dentate nucleus, (d, i-j) putamen, (e, f) hippocampus, (g) thalamus, (h) E200K-129M thalamus. (a) Finely granular (synaptic) pattern of PrPSC accumulation occurs in layers V-VI, with a few larger PrP ${ }^{S C}$ deposits (arrow). (b) H \& E stain reveals vacuolation mostly in cortical layers V-VI. (c) A cerebellar dentate nucleus neuron shows granular deposits of $\mathrm{PrP}^{\mathrm{Sc}}$ inside and around the perikarya and processes. (d) Many punctate linear and curvilinear arrays of $\mathrm{PrP}^{\mathrm{SC}}$ were located in the putamen. (e) Moderate to severe PrPSc accumulation is shown in the hippocampus, where (f) $\mathrm{H}$ \& $\mathrm{E}$ stain shows no vacuolation (the same area as E). (g) H \& E stain shows severe neuronal loss and reactive astrocytosis with mild vacuolation in the medial nucleus of thalamus (a representative astrocyte marked with an arrow). (h) H \& E stain shows small vacuoles but neither neuronal loss nor reactive astrocytosis in the medial nucleus of thalamus of an E200K-129M patient (a representative neuron marked with an arrow). (i) $\mathrm{PrP}^{\mathrm{Sc}}$ (red fluorescence) in the linear and curvilinear arrays contacts dendrites stained for MAP-2 (green fluorescence) along its course. (j) Some of PrPSc (red fluorescence) in the arrays is co-localized (yellow fluorescence, arrowheads) with synaptophysin (green fluorescence). Other $\operatorname{PrP}^{\mathrm{Sc}}$ staining, however, is not co-localized, but in close proximity to synaptophysin., suggesting it is near pre-synaptic axonal terminals. Bars below $\mathbf{b}$ and $\mathbf{c}, 50 \mu \mathrm{m}$. Bar below d, $30 \mu \mathrm{m}$ applying also to $\mathbf{a}$. Bar below e, $100 \mu \mathrm{m}$, applying also to f. Bar below $\mathbf{g}$, $50 \mu \mathrm{m}$ applying also to h. Bar below i, $20 \mu \mathrm{m}$ applying also to $\mathbf{j}$. Layers of the cerebral cortex are indicated. "wm" indicates white matter.

representation of diglycosylated $\mathrm{PrP}^{\mathrm{Sc}}$ and underrepresentation of unglycosylated $\operatorname{PrP}^{\mathrm{Sc}}$ species (Figure 6a).

Comparison to E200K cases evaluated through the NPDPSC To compare the clinical and pathological phenotype of our E200G-129V(M) (trans M) case to that of E200K, we selected three E200K-129V(M) cases for whom sufficient clinical data were available from among the six NPDPSC cases used for histopathological examination. Table 3 summarizes the clinical and pathological findings of these NPDPSC E200K-129V(M) cases, ages 37-67. These three NPDPSC E200K-129V(M) cases all initially 


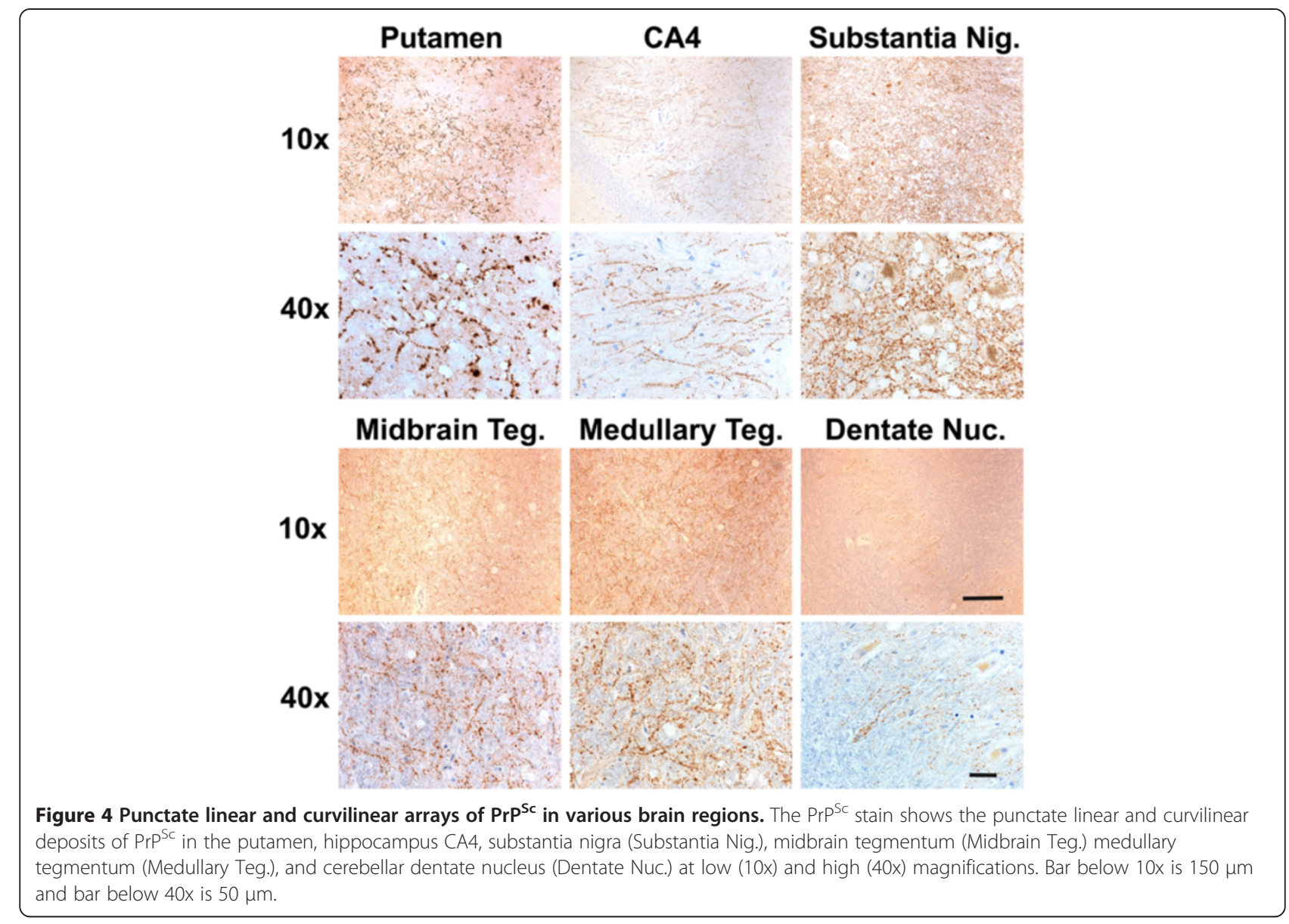

manifested with gait difficulty followed by memory decline, and progressed rapidly over 7-9 months. One case had myoclonus in the arms and two cases showed slowing on EEG. All three cases reportedly showed reduced striatal diffusion on brain MRI but no definitive cortical ribboning was reported (although cortical ribboning is often missed [16]). Pathological examination of these three NPDPSC E200K-129V(M) cases showed classical features of CJD throughout the cerebral cortex, striatum, hippocampus, and cerebellum and type $2 \mathrm{PrP}^{\mathrm{Sc}}$. These three cases (as well as the three other histopathologically-analyzed cases without sufficient clinical history) also showed mild to moderate, punctate linear and curvilinear $\operatorname{PrP}^{\mathrm{Sc}}$ deposits in the midbrain and cerebellar dentate nuclei. In addition, this punctate linear and curvilinear $\operatorname{PrP}^{\mathrm{Sc}}$ deposition pattern was also observed in most E200K-129M(V) cases (8 of 9 cases examined), particularly in the putamen, globus pallidus, midbrain, cerebellar dentate nucleus, and hippocampus (Table 4).

Notably, all three NPDPSC E200K-129V(M) cases showed marked atrophy of the cerebellum (global in two cases and focal in one case), which exhibited severe diffuse, fine synaptic $\mathrm{PrP}^{\mathrm{Sc}}$ deposits (occasional small $\mathrm{PrP}^{\mathrm{Sc}}$ aggregates present but no plaque-like formation), vacuolation and reactive astrocytosis in the cerebellar cortex. Two NPDPSC E200K-129V(M) cases which did not have clinical information and were used for histopathological exam, also showed very similar cerebellar pathology to these three cases (not shown). One case which was not included in this clinical and pathological comparison due to insufficient clinical information available (Table 3, Legend) showed focal $\mathrm{PrP}^{\mathrm{Sc}}$ deposits with a perpendicular orientation to the cerebellar pial surface. Table 4 compares pathological findings of our E200G case and E200K-129V(M) and E200K-129M(V) (E200K; taken from the literature and the NPDPSC cases).

For a comparative molecular study of $\mathrm{PrP}^{\mathrm{Sc}}$, we included NPDPSC brains from E200K-129V(M), E200K-129M(V), sCJDMM1 and sCJDVV2. E200K-129V(M) $\mathrm{PrP}^{\mathrm{Sc}}$ comigrated with the $\operatorname{PrP}^{\mathrm{Sc}}$ type 2 of E200G-129V(M). A fragment of $\sim 17 \mathrm{kDa}$ was detected in the cerebellum of two E200K-129V(M) (one case shown in Figure 6a, line 3), but not in our patient, nor in $\mathrm{E} 200 \mathrm{~K}-129 \mathrm{M}(\mathrm{V})$. $\mathrm{PrP}^{\mathrm{Sc}}$ from one E200K-129M(V) case, however, migrated about $1 \mathrm{kDa}$ slower, to $\sim 20 \mathrm{kDa}$ (Figure 6a, lines 9-11) matching $\operatorname{PrP}^{\mathrm{Sc}}$ type 1, whereas another E200K-129M(V) case showed type $2 \mathrm{PrP}^{\mathrm{Sc}}$ (Figure 6a, lines 12-13). To better understand the spectrum of $\operatorname{PrP}^{\mathrm{Sc}}$ types in E200K CJD, we selected 
Table 2 Lesion profiles of the E200G case

\begin{tabular}{|c|c|c|c|}
\hline Pathology $\backslash$ Brain regions & $\operatorname{PrP}^{\mathrm{Sc}}$ deposition $^{\mathrm{a}}$ & Vacuolation $^{\text {b }}$ & Reactive astrocytosis $^{c}$ \\
\hline \multirow[t]{3}{*}{ Frontal } & Layers $5,6++/+++(\mathrm{S} / \mathrm{PL} / \mathrm{FG})$ & Layer $6+++$ & Pattern1: layer $1+$ \\
\hline & & Layers $2-5++$ & Pattern 2: layers 1-4 ++ \\
\hline & Layers 1-4 + (FG) & & Pattern 3: layers 1-6 +++ \\
\hline \multirow[t]{3}{*}{ Parietal } & Layers 5, $6++$ & Layers 5-6 ++ & Pattern1: layer $6++$ \\
\hline & $(\mathrm{S} / \mathrm{PL} / \mathrm{FG})$ & Layers 2-4 + & Pattern 2: layers $2-6++$ \\
\hline & Layers 1-4 + (FG) & & \\
\hline \multirow[t]{6}{*}{ Temporal } & Layers $5,6++/+++(\mathrm{FG})$ & Lattern 1: & Pattern 1: layers $1-5++++$ \\
\hline & Layers 1-4 ++ (FG) & Layers 3-6 +++ & Pattern 2: layers $1-5+/++$ \\
\hline & & Layer 2 SS & \\
\hline & & Pattern 2: & \\
\hline & & Layers 5-6 +++ & \\
\hline & & Layers 2-4 ++++ (SS) & \\
\hline \multirow[t]{2}{*}{ Occipital } & Layers 5, $6+(\mathrm{FG})$ & Layer $6+$ & Layers 1-6 -/+ \\
\hline & Layers 1-4 -/+ (FG) & & \\
\hline \multirow[t]{3}{*}{ Cingulate } & Layers 1-6 +++ (FG) & Layers 2-3 ++ & Layers 2-6 ++++ \\
\hline & & Layers $4-5+++$ & \\
\hline & & Layer $6++$ & \\
\hline \multirow[t]{2}{*}{ Insula } & Layers 5, $6+++(F G)$ & Layers 5-6 +++ & Layers $1-4+++$ \\
\hline & Layers $1-4++(\mathrm{FG})$ & Layers 2-3 ++ & Layers 5, 6 - \\
\hline Caudate & $+++(S, F G)$ & +++ & +++ \\
\hline Putamen & $+++(S, F G)$ & +++ & +++ \\
\hline \multirow[t]{2}{*}{ Globus pallidus } & Ext. $+++(F G)$ & Ext. + & Ext.++/+++ \\
\hline & Int. $++/+++(F G)$ & Int. + & Int. ++ \\
\hline \multirow[t]{3}{*}{ Thalamus $^{\mathrm{d}}$} & Rostral: med.+/++ (S), lat. - & Rostral: med.++, lat.-/+ & Rostral: med. $++/+++$, lat. $+/++$ \\
\hline & Middle: med. + (S), lat. - & Middle: med.++, lat.+ & Middle \& caudal: med. $++/+++$, lat. $-/+$ \\
\hline & Caudal: med. $1+$ but focal 2+, lat. - & Caudal: med.++/+++, lat. + & \\
\hline Amygdala & $++/+++(\mathrm{FG})$ & +++ & $++/+++$ \\
\hline \multirow[t]{10}{*}{ Hippocampus $^{d}$} & Dentate gyrus, $\mathrm{CA} 4, \mathrm{CA} 3$, and $\mathrm{CA} 2:-/+$ & CA4, CA3, CA2, and CA1 prox.- & $\mathrm{CA} 4, \mathrm{CA} 3++$ \\
\hline & & & CA2, CA1 prox.- \\
\hline & CA1: prox. ++, CA1 dist. $+++(F G)$ & CA1 dis. ++ & CA1 dis. ++ \\
\hline & Subiculucm: +++ & Subiculum: & Subiculum ++, \\
\hline & Entorhinal cortex: layers $5,6++/+++$ & Layer $4+++$ & Entorhinal cortex: layers $2-6++$ \\
\hline & & Layer $2+/++$ & \\
\hline & Layers $1-4-/++(F G)$ & Entorhinal cortex & Transentorhinal cortex: layers 2-6 +++ \\
\hline & Transentorhinal cortex: layers 1-6 +++ (FG) & : layers $2,4+++$ & \\
\hline & & Transentorhinal cortex & \\
\hline & & : layers 2-6 +++ & \\
\hline \multirow[t]{3}{*}{ Cerebellum } & Molecular and granular layers $-/+$ & Molecular and granular & Molecular layer $++/+++$ \\
\hline & & Layers - dentate nucleus + & Granular layer $+/++$ \\
\hline & Dentate nucleus + & & Dentate nucleus + \\
\hline \multirow[t]{2}{*}{ Midbrain } & Periaqueductal gray and tegmentum + (FG) & Periaqueductal gray ++ & Periaqueductal gray + \\
\hline & & Tegmentum + & Tegmentum ++/+++ \\
\hline
\end{tabular}


Table 2 Lesion profiles of the E200G case (Continued)

\begin{tabular}{llll}
\hline Substantia nigra & $++/+++(F G)$ & ++ & $+/++$ \\
Medulla & Tegmentum $++(F G)$ & Tegmentum + & Tegmentum + \\
& Inf. olive $++/+++(F G)$ & Inf. olive - & Inf. olive + \\
\hline
\end{tabular}

${ }^{\mathrm{a}}$ PrP ${ }^{\mathrm{Sc}}$ deposition scored on a 4-level scale: - absent, + mild, ++ moderate, +++ severe; ${ }^{\mathrm{b}}$ Vacuolation scored on a 5 -level scale - absent, + mild, ++ moderate, +++ moderately severe, $++++/$ SS very severe/status spongiosis. ' Reactive Astrocytosis scored on a 5 -point scale - absent, + mild, ++ moderate, +++ moderately severe, ++++ very severe. ${ }^{d}$ data shown is from UCSF pathological analysis. NPDPSC analyses were generally in agreement with UCSF analyses except NPDPSC found +++ $\mathrm{PrP}^{\mathrm{SC}}$ in medial thalamus and hippocampus. Abbreviations: S Synaptic, PL Plaque-like, FG Finely granular, SS Status spongiosus, ext. Externa, int. Interna, med. Medial, lat. Lateral, prox. Proximal, dis. Distal, inf. Inferior.

additional NPDPSC E200K cases for whom Western blots were available. Among seven E200K-129V(M) cases, 86\% were type $2(n=6)$ and $14 \%$ were both types 1 and $2(n=1)$ and all E200K-129V(V) cases were type $2(\mathrm{n}=4)$. Among the E200K-129M(V) cases, $47 \%$ were type $1(n=9), 26.5 \%$ each were type $2(n=5)$ and both types 1 and $2(n=5)$. Among the E200K-129M(M) cases, 91\% were type 1 ( $\mathrm{n}=49$ ) but $9 \%$ were both type 1 and $2(\mathrm{n}=5)$ (Table 5$)$.

Having found that each group had diverse $\mathrm{PrP}^{\mathrm{Sc}}$ types, we examined whether codon 129 polymorphism and $\mathrm{PrP}^{\mathrm{Sc}}$ types affected clinical manifestations (age at disease onset and disease duration) of E200K CJD (Table 5). We found that the E200K-129V cohort had the longer disease duration than the E200K-129M $(9 \pm 4$ vs. $5 \pm 4.5$ months, $\mathrm{p}=0.024)$. But among the E200K-129V cohort, there was no difference in the duration between $129 \mathrm{~V}(\mathrm{M})$ and $129 \mathrm{~V}(\mathrm{~V})$ cases $(8 \pm 1$ vs.10 $\pm 6, p=0.75)$. Interestingly, among the E200K$129 \mathrm{M}$ cohort, cases with $129 \mathrm{M}(\mathrm{V})$ had the longer duration than those with $129 \mathrm{M}(\mathrm{M})(9 \pm 7$ vs. $4 \pm 2$ months, $\mathrm{p}=0.004)$. We also found that among the E200K-129M(V), cases with $\mathrm{PrP}^{\mathrm{Sc}}$ type 2 had the longer duration than those with type 1 ( $16.5 \pm 8$ vs. $5.5 \pm 3$ months, $\mathrm{p}=0.036)$. But the age at disease onset was not affected by either codon 129 polymorphism or $\mathrm{PrP}^{\mathrm{Sc}}$ types in E200K patients of both haplotypes (E200K-129V vs. E200K-129M, p = 0.21; E200K$129 \mathrm{~V}(\mathrm{M})$ vs. E200K-129V(V), $\mathrm{p}=0.83$; E200K-129M(V) vs.
E200K-129M(M), p = 0.18; E200K-129M(V) PrP ${ }^{\text {Sc }}$ type 2 vs. E200K-129M(V) PrP ${ }^{\mathrm{Sc}}$ type $\left.1, \mathrm{p}=0.45\right)$.

On the other hand, the representations of the di-, monoand unglycosylated isoforms of $\operatorname{PrP}^{\mathrm{Sc}}$ in E200K-129V(M) and $-129 \mathrm{M}(\mathrm{V})$ were similar to that of our E200G patient, characterized by the prominent representation of diglycosylated $\operatorname{PrP}^{\mathrm{Sc}}$ and underrepresentation of unglycosylated $\mathrm{PrP}^{\mathrm{Sc}}$ species (Figure 6a-b); the amounts of the three glycoforms (di-, mono-, and unglycosylated $\mathrm{PrP}^{\mathrm{Sc}}$ ), expressed as percent distribution of each form, were 51:38:11 in our patient, 52:39:9 in E200K-129V, 49:40:11 in E200K-129M$\mathrm{PrP}^{\mathrm{Sc}}$ type 1, and 54:38:8 in and E200K-129M-PrP ${ }^{\mathrm{Sc}}$ type 2 (Figure 6b). As expected, the $\operatorname{PrP}^{\mathrm{Sc}}$ glycoform ratios associated with our patient and the E200K differed from those of sCJDMM1 and sCJDVV2 in which the monoglycosylated $\mathrm{PrP}^{\mathrm{Sc}}$ was predominant (sCJDMM1: 21:46:33; sCJDVV2: 35:49:16) (Figure 6b).

\section{Materials and methods}

The work in this paper was approved by the UCSF Committee on Human Research and University Hospitals Case Medical Center Institutional Review Board. The proband and her sibling were subjects in a UCSF research study on human prion disease that includes an extensive standardized clinical evaluation. Autopsy and sampling of material for histopathological analyses of

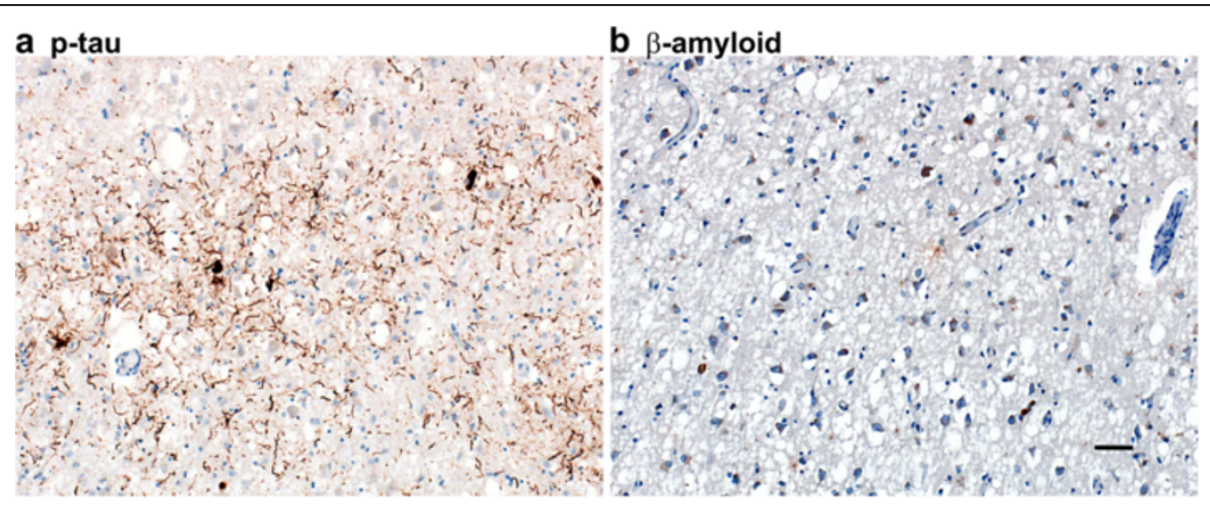

Figure 5 Hyperphosphorylated tau and $\beta$-amyloid $(A \beta)$ immunoreactivity in the E200G case. (a) Many hyperphosphorylated tau positive neuropil threads and four neuronal cell bodies are found in the entorhinal cortex layers 3 and 4 . (b) No A $\beta$ plaques are seen but many neuronal cell bodies are A $\beta$ positive in the entorhinal cortex layers 3 and 4 . Bar in $\mathbf{b}$ represents $100 \mu \mathrm{m}$ and applies also to $\mathbf{a}$. 


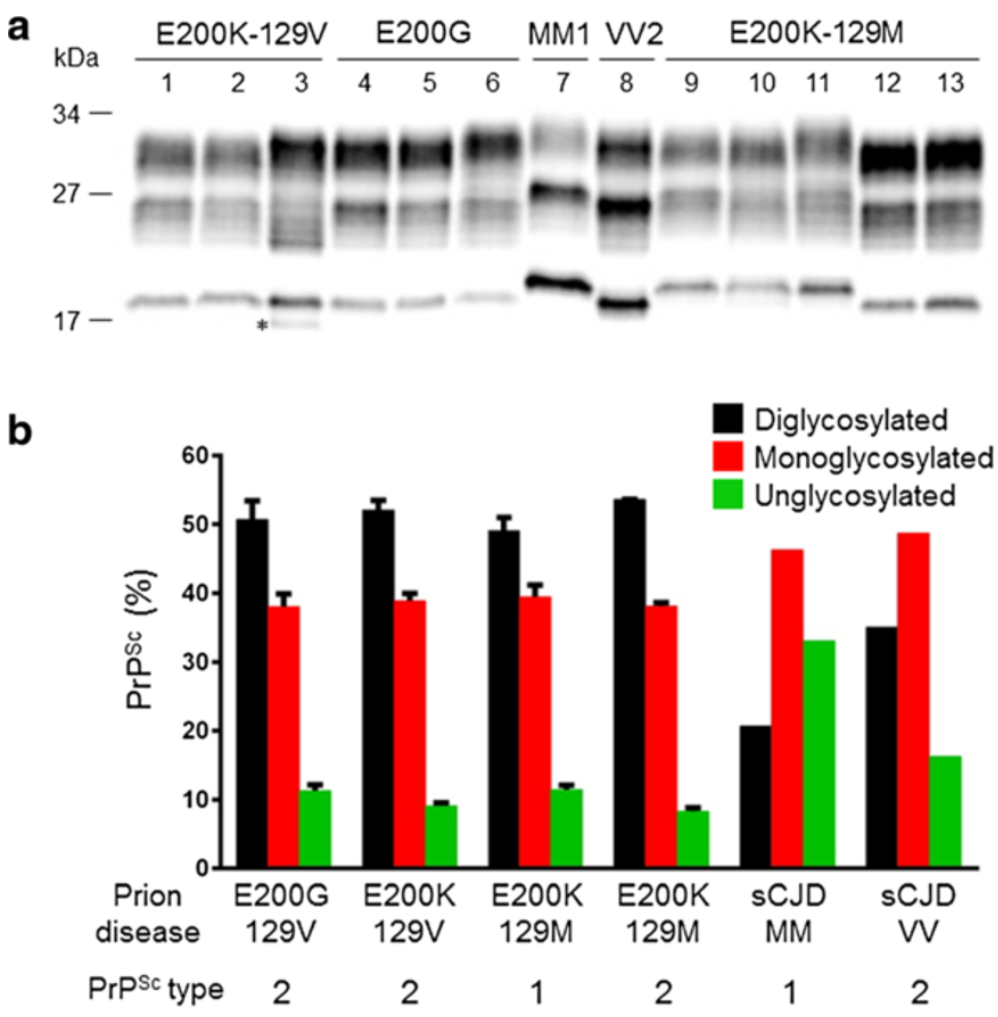

Figure 6 Prion typing. Determination of electrophoretic mobility and PrPSc glycoform ratio in gPrD with E200G and E200K mutations. (a) Western blot analysis of PrPSc from an E200K-129V patient (lanes 1-3), our E200G case (lanes 4-6), an E200K-129M patient associated with PrPSc type 1 (lanes 9-11) and an E200K-129M patient associated with PrP ${ }^{S C}$ type 2 (lanes 12-13). The mobility of the unglycosylated PrP ${ }^{S C}$ from E200G is $\sim 19 \mathrm{kDa}$ as that of PrPSC type 2 and matches the corresponding mobility observed in E200K-129V and E200K-129M associated with PrPSC type 2. A fragment of $\sim 17 \mathrm{kDa}$ (indicated by the asterisk) was detected in the cerebellum of the two E200K-129V. PrPSC from SCJDMM1 (lane 7) and sCJDW2 (lane 8) subtypes have been loaded as control. Frontal (lanes 1, 4, 7-9 and 12), parietal (lane 5), occipital (lanes 2, 10 and 13) cortices and cerebellum (lanes 3, 6 and 11) were examined. (b)The amounts of di-, mono- and unglycosylated PrP ${ }^{\text {Sc }}$ glycoforms expressed as percentage of the total PrPSc are virtually identical in all cases associated with the E200G and E200K mutations, but they differ from those of SCJDMM1 and SCJDW2. Bar graphs are expressed as mean \pm SEM of the two cortical regions from cases of E200K-129M $(n=3)$, E200K-129V $(n=4)$, and E200G, and one region from SCJDMM1 $(n=1)$ and SCJDW2 $(n=1)$.

various brain regions were performed as previously described [18] including the thalamus and cerebellum. One half of the brain was frozen, the other fixed in formalin [19]. Immunohistochemistry on fixed sections and histoblot on frozen sections were performed as previously described [20-24]. Histologic sections were evaluated and assessed for $\operatorname{PrP}^{\mathrm{Sc}}$ deposition with 3F4 antibody (from Dr. Stanley Prusiner), vacuolation with hematoxylin and eosin staining, reactive astrocytosis with GFAP staining (polyclonal rabbit, catalog \# Z0334, Dako, Carpinteria, CA), and dendritic staining with MAP-2 antibody (polyclonal rabbit, catalog \# AB5622, Millipore, Billerica, MA), as previously described $[18,19,22]$. Neuronal loss was judged by visual assessment as absent, mild, moderate or severe. The presence of other proteinopathies was assessed by antibodies for hyperphosphorylated tau (CP13, from Peter Davies), $\beta$-amyloid (mouse anti- $\beta$ amyloid monoclonal Ab (mAb), 4G8, catalog\# NE1002, Millipore), $\alpha$-synuclein (mouse mAb, catalog\# ab27766,
Abcam, Cambridge, MA), TDP43 (rabbit polyclonal, catalog \# 10782-2-AP, Proteintech Group, Inc. Chicago, IL), and ubiquitin (rabbit polyclonal, catalog \# Z0458, Dako), as previously described [25].

PRNP analyses and Western blot for typing of the proteinase $\mathrm{K}(\mathrm{PK})$-resistant $\mathrm{PrP}^{\mathrm{Sc}}$ were performed by the National Prion Disease Pathology Surveillance Center (NPDPSC) (Cleveland, OH) [2]. For a comparative molecular study of prion typing, frozen brains were collected by the NPDPSC from genetic prion disease $(\mathrm{gPrD}) \mathrm{E} 200 \mathrm{~K}-129$ $\mathrm{V}(\mathrm{n}=4)$, E200K-129M ( $=3), \operatorname{sCJDMM1}(\mathrm{n}=1)$ and sCJDVV2 $(\mathrm{n}=1)$. All E200K cases selected from the NPDPSC database were heterozygous at codon 129; Due to the rarity of E200K-129 V cases, all available cases were used without applying any inclusion/exclusion criteria. E200K-129M had age of disease onsets similar to that of our E200G case, with disease durations felt to be representative of most of the E200K NPDPSC cohort. For histopathological comparison, immunohistochemistry 
Table 3 Clinical features of NPDPSC E200K-129V (trans M) cases*

\begin{tabular}{lll}
\hline & Patient C & Patient $\mathbf{E}$ \\
\hline Age/gender & 37 yo/male & 57 yo/female \\
Age of onset & 37 yo & 57 yo \\
Duration of illness & 9 months & 8 months \\
First symptom & Gait difficulty & Gait difficulty and nonspecific dizzy feeling \\
$\begin{array}{l}\text { Other symptoms and } \\
\text { cognitive tests }\end{array}$ & Speech difficulty; dysarthria & Blurry and double vision at 2-3 months \\
& MOCA 19/30 at 4 months & Curled hands, clumsy hands
\end{tabular}

Patient F

67 yo/female

67 yo

7 months

Veering to the left and worsening gait

Weak voice,

Hands tremor,

Unable to write

Short term memory decline at 2-3 months

MMSE 25/30 (no recall, no copy of design) at 4 months,

Cognition deterioration

Myoclonus and other abnormal Myoclonus + in arms

neurological findings

EEG

N/A

Brain MRI

Read normal at 2 months.

At 3 months, reported as symmetrical T2 and DWI hyperintensity in the caudate

putamen, and pulvinar

$\begin{array}{lll}\text { Other imaging } & \text { Unremarkable C, T, and L spine MRIs } & \text { Disc bulging on C-spine MRI } \\ \text { CSF profile } & \text { Clear, colorless, WBC 0, protein 61(15-60), } & \text { Positive 14-3-3 }\end{array}$

glucose $65(45-75)$

\section{Positive 14-3-3}

\section{tau $20360 \mathrm{pg} / \mathrm{mL}$}

Other labs

Serum paraneoplastic panel negative

PrP ${ }^{\text {SC }}$ type

Family history for CJD

MMSE 19/30 (missing points on orientation and recall) at 4 months

Myoclonus - vertical gaze palsy+

Intermixed bursts of delta and theta activity at 4 months

Reported as only periventricular white matter changes at 2 month.

Restricted diffusion in the caudate at 4 months

\section{tau $14746 \mathrm{pg} / \mathrm{mL}$}

MOCA $10 / 30$ at 4 months

MMSE 27/30 at 5 months (remote recall 0/3)

Myoclonus - postural tremor+, bradykinesia +

Right temporal slowing at 4 months

Reported as high T2 signal in the cerebellar gray matter and vermis, cerebellar atrophy at 3 months.

At 4 months, restricted diffusion in the caudate bilaterally, subtle restriction in the thalamic

pulvinar area, left greater than right, and questionable

high cortical intensity in the mesial frontat and parieta

high contical intensity in the mesial frontal and parietal

findings, increased signal in the entire cerebellum on DW

findings, increased signal in the

Clear, colorless, WBC 0, protein 46 (12-60), glucose 84 $(40-70)$

\section{4-3-3 $4.5 \mathrm{ng} / \mathrm{mL}$}

$(\mathrm{nl}<1.5 \mathrm{ng} / \mathrm{mL}$, Mayo clinic)

CSF paraneoplastic panel: negative (Mayo clinic)

Serum paraneoplastic panel negative

Positive for progressive movement problems and

dementia: 2 family members + for genetic testing

Father died of CJD at age 69 within 6 months 


\section{Table 3 Clinical features of NPDPSC E200K-129V (trans M) cases* (Continued)}

Histological and

immunohistochemical findings

\section{Vacuolation and reactive astrocytosis}

1) Intense in the cerebral neocortex, basa ganglia, hippocampus, and cerebellum

2) Mild to moderate vacuolation in the thalamus

3) Vacuolation more severe in the basal

ganglia than the cerebral cortex and thalamus

\section{PrP ${ }^{\mathrm{Sc}}$ deposits}

1) Diffuse and plaque like deposits in the

cerebral cortex

2) Presence of intraneuronal $\operatorname{PrP}^{S c}$ deposit

3) Moderate PrP ${ }^{S c}$ deposits in the

hippocampus and entorhinal cortex

4) Severe diffuse PrP $\mathrm{P}^{\mathrm{Sc}}$ deposits in the cerebellar

molecular and granular layers, occasional small

$\mathrm{PrP}^{\mathrm{SC}}$ aggregates in the cerebellar granular laye

Marked global atrophy of the cerebellum

Similar to patient $\mathbf{C}$ but with less intense PrP ${ }^{S C}$

immunostaining and no plaque-like PrP ${ }^{S C}$

formations.; Global cerebellar atrophy
Similar to patient $\mathbf{C}$ but with less intense PrP $\mathrm{SC}$

immunostaining and no plaque-like PrP ${ }^{\text {SC }}$ formations:

Focal cerebellar atrophy

5) Linear and curvilinear PrP ${ }^{S c}$ deposits in the midbrain and cerebellar dentate nucleus

* There were six E200K-129 V NPDPSC cases (A-F). No clinical information was available for Cases A and B. Case D, an 85 yo woman with dementia and known family history of E200K presenting with confusion but no other known clinical history, was not included in the table due to limited clinical information. Her MRI reportedly showed atrophy, chronic, microvascular ischemic change. Pathology revealed senile plaques of other known clinical history, was not included in the table due to lin. Alzhe also had foal Prpsc deposit with a perpendicular orientation to the cere 2. N/A = not available. 
Table 4 Summary of histopathological and molecular comparison between the E200G and E200K cases

\begin{tabular}{|c|c|c|c|c|c|c|c|c|c|c|c|c|}
\hline \multirow[b]{2}{*}{ Pathology ${ }^{a} \backslash$ Brain regions } & \multicolumn{4}{|c|}{ E200G-129V (M) } & \multicolumn{4}{|c|}{ E200K-129V(M) [17] } & \multicolumn{4}{|c|}{ E200K-129M(V) $[1,8,14]$} \\
\hline & $\mathrm{A}$ & B & $\mathrm{C}$ & D & $\mathrm{A}$ & B & $\mathrm{C}$ & D & $A$ & B & $\mathrm{C}$ & D \\
\hline \multirow[t]{2}{*}{ Cortex } & +++ & +++ & +++ & $++/+++$ & $++/+++^{c}$ & $+++^{\mathrm{b}}$ & $\mathrm{n} / \mathrm{a}$ & $+++^{\mathrm{b}}$ & $+++^{d}$ & $+/++^{e}$ & $+++^{\mathrm{d}}$ & $++++^{d}$ \\
\hline & & & & & & & & & $+/++^{e}$ & & $+/++^{e}$ & $+/++^{\mathrm{e}}$ \\
\hline \multirow[t]{2}{*}{ Striatum } & +++ & +++ & +++ & $++/+++$ & $++/+++^{c}$ & $+++^{\mathrm{b}}$ & $\mathrm{n} / \mathrm{a}$ & $+++^{\mathrm{b}}$ & $++^{d}$ & $++^{e}$ & $++^{d, e}$ & $++^{d, e}$ \\
\hline & & & & & & & & & $++/+++^{e}$ & & & \\
\hline \multirow[t]{2}{*}{ Hippocampi } & $++/+++$ & - & - & - & $+^{\mathrm{b}}$ & $++/+++^{\mathrm{b}}$ & $\mathrm{n} / \mathrm{a}$ & $+++^{\mathrm{b}}$ & $++^{e}$ & $+^{e}$ & $+^{e}$ & $+^{e}$ \\
\hline & & & & & & & & & & $++/+++^{\mathrm{b}}$ & & \\
\hline \multirow[t]{2}{*}{ Thalamus } & +++ & +/++ & +++ & +++ & $++/+++^{c}$ & $+t^{\mathrm{b}}$ & $-\mathrm{b}$ & $-b$ & $++/+++^{e}$ & $++^{e}$ & $++^{e}$ & $++^{e}$ \\
\hline & & & & & & & & & & $t^{\mathrm{b}}$ & $-\mathrm{b}$ & $-\mathrm{b}$ \\
\hline \multirow[t]{2}{*}{ Cerebellum } & + & + & +/++ & ++ & $++/+++^{\mathrm{b}}$ & $+++^{\mathrm{b}}$ & $\mathrm{n} / \mathrm{a}$ & $+++^{\mathrm{b}}$ & $++^{d}$ & $+^{e}$ & $++^{d}$ & $++^{d}$ \\
\hline & & & & & $+++^{c}$ & & & & $++^{e}$ & & $+^{e}$ & $+^{e}$ \\
\hline Vacuole size, mean & & 14. 9 & & & & 11.9 & & & & 11.8 & & \\
\hline (range $\mu \mathrm{m}$ ) & & $(4-108)^{b}$ & & & & $(4-72)^{b}$ & & & & $(4-69)^{b}$ & & \\
\hline \multirow[t]{3}{*}{ PrP ${ }^{S c}$ staining pattern } & $\begin{array}{l}\text { Finely granular } \\
\text { synaptic }+++\end{array}$ & & & & $\begin{array}{l}\text { Finely granular } \\
\text { synaptic }++/+++^{b, c}\end{array}$ & & & & Finely granular synaptic $+++^{\mathrm{e}, \mathrm{f}}$ & & & \\
\hline & Plaque-like + & & & & Plaque $++/+++^{b, c}$ & & & & Plaque-like $++/+++^{e},+^{f}$ & & & \\
\hline & Intra-neuronal + & & & & Intra-neuronal $+{ }^{b}$ & & & & Intra-neuronal $++/+++^{\mathrm{e}}$ & & & \\
\hline \multirow{8}{*}{$\begin{array}{l}\text { Regions with linear and } \\
\text { curvilinear arrays of } \operatorname{PrP}^{S c}\end{array}$} & Striatum, hippocampi & & & & Put, GP(20\%) & & & & Put, GP & & & \\
\hline & & & & & SN, PAG & & & & $(12.5 \%)$ & & & \\
\hline & SN & & & & $(67 \%)$ & & & & CA4 of hippo (37.5\%) & & & \\
\hline & MT & & & & $\operatorname{CDN}(100 \%)^{\mathrm{b}}$ & & & & SN, PAG & & & \\
\hline & PAG & & & & & & & & $(100 \%)$ & & & \\
\hline & MION & & & & & & & & & & & \\
\hline & CDN & & & & & & & & & & & \\
\hline & & & & & & & & & $\operatorname{CDN}(80 \%)^{b}$ & & & \\
\hline \multirow[t]{3}{*}{ PrPsc type } & 2 & & & & $2^{c}$ & & & & $1(47 \%)$ & & & \\
\hline & & & & & $2(86 \%), 1+2(14 \%)^{b}$ & & & & $2(26.5 \%)$ & & & \\
\hline & & & & & & & & & $1+2(26.5 \%)^{b}$ & & & \\
\hline
\end{tabular}

Abbreviations and Definitions: ${ }^{\mathrm{a} A} \mathrm{PrP} \mathrm{P}^{\mathrm{Sc}}$ deposit, $B$ Vacuolation, $C$ Neuronal Loss, $D$ Reactive Astrocytosis, $S N$ Substantia nigra, MT Midbrain tegmentum, PAG Periaqueductal gray matter, MION Medullary inferior olivary nucleus, CDN Cerebellar dentate nucleus, Put Putamen, GP Globus pallidus, - absent, + mild, ++ moderate, +++ severe, ${ }^{b}$ NPDPSC analysis in this study, ${ }^{c}$ from reference [17] $(\mathrm{n}=1),{ }^{\mathrm{d}}$ from reference [1], ${ }^{\mathrm{e}}$ from reference [14] $(n=14),{ }^{f}$ from reference [8], $n / a$ not available. 
Table 5 Comparison of disease duration and age at disease onset, and PrP ${ }^{S C}$ types between different E200K haplotypes

\begin{tabular}{|c|c|c|c|c|c|c|c|c|c|c|}
\hline \multirow{2}{*}{$\begin{array}{l}\text { Haplotypes } \\
\text { (129 cis) }\end{array}$} & \multirow{2}{*}{$\begin{array}{l}\text { Trans } \\
\text { codon } \\
129 \\
\end{array}$} & \multirow[t]{2}{*}{$\mathrm{n}$} & \multicolumn{2}{|c|}{ Type 1 PrP ${ }^{S c}$} & \multicolumn{2}{|c|}{ Type 2 PrPSc } & \multicolumn{2}{|c|}{ Type $1 \& 2$ PrP } & \multicolumn{2}{|l|}{ All PrP ${ }^{S c}$ Types } \\
\hline & & & $\begin{array}{l}\% \\
\text { type } 1\end{array}$ & $\begin{array}{l}\text { Disease duration } \\
\text { (mean } \pm \mathrm{SD} \text {; range) }\end{array}$ & $\begin{array}{l}\% \\
\text { type } 2\end{array}$ & $\begin{array}{l}\text { Disease duration } \\
\text { (months, mean } \pm \mathrm{SD} \text {; range) }\end{array}$ & $\begin{array}{l}\% \text { types } \\
1 \text { and } 2\end{array}$ & $\begin{array}{l}\text { Disease duration } \\
\text { (months, mean } \pm \mathrm{SD} \text {; range) }\end{array}$ & $\begin{array}{l}\text { Disease duration } \\
\text { (months, mean } \pm \mathrm{SD} \text {; range) }\end{array}$ & $\begin{array}{l}\text { Age at onset } \\
\text { (years mean } \pm S D \text {; range) }\end{array}$ \\
\hline \multicolumn{11}{|c|}{ E200K-129V } \\
\hline & M & 7 & 0 & - & $86 \%$ & $8 \pm 1$ & $14 \%$ & 10 & $8 \pm 1$ & $56 \pm 12$ \\
\hline & & & & & $(n=6)$ & (7-9) & $(n=1)$ & & $(7-10)$ & $(37-67)$ \\
\hline & V & 4 & 0 & - & $100 \%$ & $10 \pm 6$ & 0 & - & $10 \pm 6$ & $54 \pm 12$ \\
\hline & & & & & $(n=4)$ & $(2-17)$ & & & $(2-17)$ & $(37-66)$ \\
\hline \multirow[t]{2}{*}{ All } & & 11 & 0 & - & $91 \%$ & $9 \pm 4$ & $8 \%$ & 10 & $9 \pm 4^{a}$ & $55 \pm 11$ \\
\hline & & & & & (10) & $(2-17)$ & $(n=1)$ & & $(2-17)$ & $(37-67)$ \\
\hline \multicolumn{11}{|l|}{ E200K-129M } \\
\hline & M & 54 & $91 \%$ & $4 \pm 2$ & 0 & - & $9 \%$ & $4 \pm 2$ & $4 \pm 2^{b}$ & $59 \pm 11$ \\
\hline & & & $(n=49)$ & $(1-12)$ & & & $(n=5)$ & $(2-7)$ & $(1-12)$ & $(40-85)$ \\
\hline & V & 19 & $47 \%$ & $5.5 \pm 3^{c}$ & $26.5 \%$ & $16.5 \pm 8^{c}$ & $26.5 \%$ & $7 \pm 4$ & $9 \pm 7^{b}$ & $63 \pm 7$ \\
\hline & & & $(n=9)$ & $(3-10)$ & $(n=5)$ & $(6.5-29)$ & $(n=5)$ & $(2-11)$ & $(2-29)$ & $(53-76)$ \\
\hline \multirow[t]{2}{*}{ All } & & 73 & $79 \%$ & $4 \pm 2$ & $7 \%$ & $16.5 \pm 8$ & $14 \%$ & $5 \pm 3$ & $5 \pm 4.5^{\mathrm{a}}$ & $60 \pm 10$ \\
\hline & & & $(n=58)$ & $(1-12)$ & $(n=5)$ & $(6.5-29)$ & $(n=10)$ & $(2-11)$ & $(1-29)$ & $(40-85)$ \\
\hline
\end{tabular}

Abbreviations and Definitions: $n$ Number of cases, Bold denotes subgroups with significant differences. ${ }^{a}$ E200K-129V had longer duration than E200K-129M ( $\left.p=0.029\right)$ : ${ }^{b}$ E200K-129M(V) lived longer than E200K-129MM $(p=0.004) ;{ }^{c}$ Among E200K-129M(V), PrP ${ }^{S c}$ type 2 lived significantly longer than type $1(p=0.036)$. All other groups did not differ significantly from each other in disease duration or age at onset. 
(IHC) also was performed on E200K-129V ( $\mathrm{n}=6)$ and E200K-129M ( $\mathrm{n}=9)$ that had disease durations with a range of 7 to 10 and 3 to 29 months, respectively. All E200K-129V cases were analyzed for IHC. The nine E200K-129M(V) (trans V) cases were chosen for IHC to be representative of the E200K-129M population. The entire NPDPSC E200K-129M(V) cohort has a mean disease duration of $9 \pm 7$ (SD) months. One long duration E200K-129M(V) case, with a disease duration of 29 months, was included because it was close in duration to our E200G case; thus the mean disease duration of these nine E200K-129M(V) cases was $12 \pm 7$ (SD) months $(10 \pm 4$ [SD] months without the long-duration 29 month case).

\section{Preparation of the brain homogenates and Western blot analysis}

Brain homogenates $(\mathrm{BH})(20 \% \mathrm{w} / \mathrm{v})$ were prepared in $1 \mathrm{X}$ Dulbecco's phosphate buffer saline (DPBS), pH 7.4, then mixed with an equal volume of $2 \mathrm{X}$ lysis buffer containing $100 \mathrm{mM}$ Tris $(100 \mathrm{mM} \mathrm{NaCl}, 0.5 \%$ Nonidet P-40, $0.5 \%$ sodium deoxycholate, $10 \mathrm{mM}$ EDTA, $100 \mathrm{mM}$ Tris- $\mathrm{HCl}, \mathrm{pH} 8.0)$. The $\mathrm{BH}$ was centrifuged at $1000 \mathrm{~g}$ for 5 minutes and the collected supernatant (S1) was digested with $10 \mathrm{U} / \mathrm{ml}$ proteinase $\mathrm{K}(\mathrm{PK})(1 \mathrm{U} / \mathrm{ml}$ equal to $20 \mu \mathrm{g} / \mathrm{ml} \mathrm{PK}$ ) at $37^{\circ} \mathrm{C}$ for 1 hour. Samples were loaded onto a $15 \%$ Tris- $\mathrm{HCl}$ polyacrylamide precast gel, transferred, then incubated with the primary prion protein antibody 3 F4 (1:40,000) for 2 hours. The prion protein was visualized by the Odyssey infrared imaging system. Densitometric analysis was performed with Odyssey application software V3.0 (LI-COR Biosciences).

\section{Vacuole size determination and statistical analysis}

The diameter $(\mu \mathrm{m})$ of the vacuoles from the cerebral cortex of E200G, E200K-129M ( $\mathrm{n}=3$ ), and E200K-129V ( $\mathrm{n}=3$ ) was measured by the software Image-Pro Plus (Media Cybernetics, Inc.). Statistical analysis was performed with GraphPad Prism 6.0 using the nonparametric Mann Whitney test with Bonferroni correction of the level of significance value $(\alpha)$ which is equal to 0.016 . For comparisons of disease duration and age of onset of various E200K haplotypes, Student t test with Welch's correction was used.

\section{Conclusions}

To our knowledge this is the first report of an E200G mutation associated with a CJD phenotype. Several reasons strongly suggest that this mutation is pathogenic. Firstly, it is in the same codon as the most common PRNP mutation, E200K causing genetic CJD. Secondly, the change from a glutamate to glycine is non-conservative, substituting a large, acidic amino acid with a side-chain, with a much smaller, non-acidic amino acid without a side-chain that might affect the propensity for misfolding of PrP. Thirdly, some of the uncommon pathological features and $\operatorname{PrP}^{\mathrm{Sc}}$ glycosylation pattern argue against this case being SCJD; prominent involvement of the deeper cortical layers observed in our patient is rare in most $\mathrm{sCJD}$, except sCJD VV2. Although our patient was MV2, there were no amyloid kurutype plaques, which is in contrast to sCJD MV2 in which amyloid kuru-type plaques are typically present [22]. Both of these findings (involvement of the deeper cortical layers and and the absence of amyloid kuru-type plaques), however, are frequently observed in E200K genetic prion disease (gPrD) [26]. Our patient had type $2 \mathrm{PrP}^{\mathrm{Sc}}$ but with the underrepresentation of the unglycosylated form (Figure 4), another characteristic of genetic prion disease, including CJD E200K and FFI, but not sCJD [27-29]. Lastly, although the father was reported to have an "alcoholic dementia" with a very rapid decline, we suspect that he died of gPrD. Not uncommonly in our gPrD families, we find that prior to a PRNP mutation being identified, some family members with gait ataxia and dementia were assumed to have had alcoholism causing cognitive impairment and gait problems.

To compare clinical and pathological phenotypes of our patient with those of E200K, we conducted extensive literature review as well as new pathological and molecular analyses on the E200K cases selected from the NPDPSC database. One might expect for E200G-129V, type $2 \mathrm{PrP}^{\mathrm{Sc}}$ to have similarities to the very rare E200K$129 \mathrm{~V}$, type $2 \mathrm{PrP}^{\mathrm{Sc}}$. We are aware of only two previously published cases of the E200K-129V; one V(M), like our patient, and the other $\mathrm{V}(\mathrm{V})$; both also had type $2 \operatorname{PrP}^{\mathrm{Sc}}$ that also were primarily diglycosylated $[17,29]$. The codon $129 \mathrm{~V}(\mathrm{~V})$ E200K patient was a 66-year-old woman with a 15.5 month course, beginning with one year of vertigo and ending after 3.5 months of rapidly progressive dementia. Similar to our patient she had no myoclonus; her EEG, however, showed focal triphasic spikes. MRI reportedly only showed ventricular enlargement, and probably did not include FLAIR or DWI [29]. The E200K-129V(M) case was a 67-year-old woman with a six-month course, beginning with gait ataxia and then rapidly progressive dementia at 4 months, but died of a pulmonary embolism. She had focal myoclonus in her later stages, but no PSWCs on EEG and MRI findings were not reported [17]. Our patient's age of onset was a decade younger (57 years) and had a longer duration (30 months), than the E200K-129V cases, but similarly had early gait disturbance and late dementia [17,29]. Despite our patient's most prominent, early and debilitating symptom of ataxia, her cerebellum was very mildly affected pathologically (Table 2). In contrast, $\operatorname{PrP}^{\mathrm{Sc}}$ accumulation was noted in the cerebellum of both published E200K$129 \mathrm{~V}$ cases; the E200K-129V(V) patient with predominant plaque-like PrP deposits [29] and the E200K-129V(M) patient with focal $\mathrm{PrP}^{\mathrm{Sc}}$ deposits with a perpendicular 
orientation to the pial surface in the cerebellar molecular layer [17].

Compared with the NPDPSC E200K-129V(M) cases (mean age at onset $56 \pm 12$ years [range 37-67 years], mean duration $8 \pm 1$ months [range 7-9 months], Table 5), however, our E200G patient had a similar age at onset, but a much longer disease duration. Common features between the E200G case and three well-characterized cases of NPDPSC E200K-129V(M) (Table 3) are initial gait difficulty followed by memory decline, striatal involvement on brain MRI, slowing on EEG, elevated CSF tau level, and type $2 \operatorname{PrP}^{\mathrm{Sc}}$. But, cortical ribboning which was mild in our E200G patient, was not observed in the NPDPSC E200K-129V(M) and myoclonus was reported in one NPDPSC E200K-129V(M) case (Table 3). In our experience, however, in most E200K cases which are reported to not have cortical ribboning on DWI/ADC MRI, we identify cortical ribboning. A majority of MRIs in CJD, unfortunately, are misread [16,30]. Pathologically, cerebellar involvement was much more severe in the NPDPSC E200K-129V(M) cases than our case. Only one of the six NPDPSC E200K-129V(M) cases examined histopathologically (Table 3, Legend) showed the similar focal $\mathrm{PrP}^{\mathrm{Sc}}$ deposits perpendicular to the cerebellar pial surface to the published E200K-V(M) patient [17]. The other five NPDPSC E200K-129V(M) cases (Table 3 and not shown) did not show either plaque-like $\mathrm{PrP}^{\mathrm{Sc}}$ deposits or focal $\mathrm{PrP}^{\mathrm{Sc}}$ deposits with a perpendicular orientation in the cerebellar cortex. We found marked atrophy in their cerebella, however, accompanied by severe diffuse $\mathrm{PrP}^{\mathrm{Sc}}$ deposits and severe vacuolation and reactive astrocytosis, which are in great contrast to the mild cerebellar involvement of our E200G patient (Tables 2 and 3). In addition, we detected another fragment of $\sim 17 \mathrm{kDa}$ of $\operatorname{PrP}^{\mathrm{Sc}}$ in the cerebellum of the two NPDPSC E200K-129V(M) cases with Western blotting, which was not observed in our patient (Figure 6). Whether the cerebellar presence of the $17 \mathrm{kDa}$ fragment is a distinctive feature of E200K-129V(M) remains to be determined. There are clearly overlapping as well as distinguishing features between our case and the E200K-129V(M) gPrD patients.

Although our patient was cis $129 \mathrm{~V}$, she had many features in common with the most prevalent form of E200K, with $129 \mathrm{M}$ cis (E200K-129M). The age at onset (57 years) in our case is consistent with those of E200K-129M, with a published mean age at onset 58 years (range $33-84$ years) $[5,8,10]$ and those of NPDPSC with $60 \pm 10$ years (range 40-85 years) (Table 5). Our patient's duration of illness (30 months), however, is longer than the published mean duration of E200K (6; range 2-41 months) and those of NPDPSC ( $5 \pm 4.5$; range 1-29 months) (Table 5) but within the published range $[5,8,10]$. Brain MRI findings of the predominant striatal involvement and mild cortical ribboning observed in our patient (Figure 2) are also common in
E200K-129M [31,32]. Pathologically, the pattern of $\operatorname{PrP}^{\mathrm{Sc}}$ deposits was diverse in our patient (synaptic, coarse granular, and plaque-like deposits) overlapping with those in Slovakian E200K-129M (synaptic pattern mainly in $129 \mathrm{MM}$ and granular or plaque-like deposits in 129MV) cases [8]. Involvement of deep cortical layer and no amyloid kuru-type plaques of $\operatorname{PrP}^{\mathrm{Sc}}$ were both present in our patient and also are in E200K-129M (Figure 3) [26].

Our case also had several differences from those typically found in E200K-129M. Our patient initially presented with gait ataxia followed by dementia, whereas dementia typically occurs first in E200K-129M $[5,8,10]$. Our patient did not develop myoclous or EEG PSWCs, which are very common in published E200K-129M cases (myoclonus in $73 \%$ and PSWCs in 75\%) [33,34]. A characteristic stripe-like pattern with a perpendicular orientation of $\mathrm{PrP}^{\mathrm{Sc}}$ deposits in the cerebellum noted in published E200K-129M [14,26,35] cases was not observed in our case. In addition, our patient had type $2 \mathrm{PrP}^{\mathrm{Sc}}$, whereas E200K-129M cases have type 1, 2 or mixture of both types $[14,29,36]$. Other differences between our patient and $\mathrm{E} 200 \mathrm{~K}$ cases examined were the larger vacuole sizes (the mean diameter of the vacuoles from E200G significantly larger than those of the NPDPSC E200K-129M and E200K-129V), no vacuolation in the hippocampus (despite abundant $\operatorname{PrP}^{\mathrm{Sc}}$ staining), and the severe involvement of the thalamus (severe atrophy, $\operatorname{PrP}^{\mathrm{Sc}}$ deposits, neuronal loss, and reactive astrocytosis, and mild vacuolation) (Figure 3). Vacuolation in the hippocampal pyramidal cell layer was observed in the NPDPSC E200K-129M (6 cases out of 7 cases examined) and $-129 \mathrm{~V}$ cases (all 6 cases examined). The thalamic changes noted in our case have been reported only in one case of E200K-129M [37] and commonly seen in sporadic and familial fatal insomnia [38,39].

In one previous study, Ht positive neuritis (93.3\%), parenchymal $A \beta$ (53.8\% but only occasional neuritic plaques) and Lewy type $\alpha$-synuclein pathology (15.4\%) were reported in E200K (all codon 129 polymorphisms, except no V(M) were represented) [14]. We found Ht-positive neuronal cell bodies and neuropil threads in the entorhinal cortex of our patient (Figure 5). This distribution of $\mathrm{H \tau}$ was found to be characteristic of great majority of SCJD and familial CJD (fCJD) cases analyzed at our center (DeArmond, Tousseyn, Bajsarowicz, et al., in preparation). It has been reported that among non-demented subjects $20-50$ years of age, $11 \%$ had limited number of Ht's in the entorhinal cortex and trans entorhinal cortex [40]. No $A \beta$ plaques were found in any regions of our patient, however (Figure 5). This is consistent with our unpublished findings that only 2 of 14 cases of fCJD had AD neuropathology (DeArmond et al., in preparation). It is also consistent with the age of death of our patient (59 years), as CJD-AD cases are found to occur almost 10 years later (DeArmond et al., in preparation). 
In the NPDPSC E200K cohort, cases with a valine at codon 129 and $\mathrm{PrP}^{\mathrm{Sc}}$ type 2 had longer disease duration (Table 5). Considering the longer duration of our patient with E200G-129V(M), PrP ${ }^{\mathrm{Sc}}$ type 2 than that of E200K$129 \mathrm{~V}(\mathrm{M}), \operatorname{PrP}^{\mathrm{Sc}}$ type 2 cases, we suspected that this novel mutation might contribute to the prolonged disease course.

One of the most unusual findings in our case was the abundant curvilinear arrays of $\operatorname{PrP}^{\mathrm{Sc}}$ in various brain regions (Figures 3 and 4). To our knowledge there is only one reported CJD case (unclear if genetic or sporadic) with a similar pattern of $\operatorname{PrP}^{\mathrm{Sc}}$ deposits [41]. We also observed this staining, however, in all NPDPSC E200K$129 \mathrm{~V}(\mathrm{M})$ and most E200K-129M(V) cases examined histopathologically in this study (Table 4).

The subcellular localization of the $\operatorname{PrP}^{\mathrm{Sc}}$ deposits to synapses and presynaptic axonal terminals might be related to transsynaptic spread of $\operatorname{PrP}^{\mathrm{Sc}}$. It remains unknown whether $\mathrm{PrP}^{\mathrm{Sc}}$ spreads along defined neuroanatomical pathways in human prion disease, which is the case in scrapie-injected mouse [42,43] and hamster models $[44,45]$. Notably, the subcortical gray matter and brain stem enriched in the curvilinear arrays of the synaptic $\mathrm{PrP}^{\mathrm{Sc}}$ in our patient are known to be preferentially vulnerable regions in progressive supranuclear palsy (PSP) [46]. This is interesting as it is now realized that pathological tau aggregates might propagate by a prion-like mechanism [47-49]. A recent functional MRI (fMRI) study in PSP showed the connectivity disruption of the same dorsal midbrain tegmentum-anchored intrinsic connectivity network (ICN) (brain stem, cerebellum, striatum and cortex) [46] as was affected pathologically in our case. The overlap of the affected brain regions and some PSP-like clinical features (gait difficulty, saccadic pursuit, slowed velocity of horizontal saccades, and parkinsonism) in our patient suggested the possibility of $\operatorname{PrP}^{\mathrm{Sc}}$ spreads through this PSP-related ICN.

As this was a single case, the spectrum of clinicopathological presentation of this novel mutation has yet to be determined. This case supports, however, the loss of glutamate at codon 200, and not its replacement with lysine, as the cause of PrP misfolding. As has been done with E200K [50], a mouse model of E200G might help further show the pathogenicity of this novel mutation. The penetrance of this E200G mutation has yet to be determined. We suspect that conformational changes of $\operatorname{PrP}^{\mathrm{Sc}}$ caused by the E200G mutation and the rare codon 129 cis valine polymorphism might contribute to the distinct clinical and pathological findings of our patient in contrast to the E200K-129M and E200K-129V subjects.

\section{Consent}

Written informed consent was obtained from the patient's next of kin for the publication of this report and all accompanying images.

\section{Competing interests}

The authors declare that they have no competing interests. Dr. Geschwind has served as a consultant for MedaCorp, The Council of Advisors, Guidepoint Global, and Neurophage.

\section{Authors' contributions}

MOK analyzed clinical data, designed the studies of immunohistochemistry $(\mathrm{IHC})$, created figures, and drafted the manuscript. IC analyzed E200K clinical data, performed all Western blots and $I H C$, created figures, and edited the manuscript. AO performed IHC. JCF, KW, TS, and JSK were involved in the collection of clinical data on the E200G case. PG contributed to the collection of E200K clinical data and editing the manuscript. BMB provided interpretation of neuropsychological data and edited the manuscript. SJD performed neuropathological analysis for the E200G case. MDG supervised the study, collected and analyzed E200G clinical data and co-wrote and edited the manuscript. All authors read and approved the final manuscript.

\section{Acknowledgements}

This work was supported by NIA/NIH R01 AG031189, P50 AG023501, NIH/NCRR UCSF-CTSI Grant Number UL1 RR024131, The Michael J. Homer Family Fund, and Alzheimer's Disease Research Center of California (ARCC) Grant 03-7527, P01 AG02132, NIH NS074317, PO1 AG14359, CDC UR8/CCU515004, The Britton Foundation. We thank Dr. Satish Viswanath (Case Western Reserve University) for his assistance in statistical analysis, Dr. Lea Grinberg (UCSF) for assistance in immunohistochemistry, as well as our patient and her family.

\section{Author details}

'Department of Neurology, Memory and Aging Center, University of California, San Francisco (UCSF), San Francisco, CA 94143, USA. ${ }^{2}$ National Prion Disease Pathology Surveillance Center (NPDPSC), Case Western Reserve University, School of Medicine, Cleveland, OH 44106, USA. ${ }^{3}$ Department of Clinical and Experimental Medicine, Second University of Naples, Naples, Italy. ${ }^{4}$ Department of Pathology, UCSF, San Francisco, CA 94117, USA. ${ }^{5}$ Forbes Norris ALS/MDA Center, Department of Neurology, California Pacific Medical Center, 2324 Sacramento St, Suite 111, San Francisco, CA 94115, USA.

Received: 21 October 2013 Accepted: 26 October 2013

Published: 12 December 2013

\section{References}

1. Kong Q, Surewicz WK, Petersen RB, et al: Inherited prion diseases. In Prion Biology and Diseases. 2nd edition. Edited by Prusiner SB. City: Cold Spring Harbor Laboratory Press; 2004:673-775.

2. Gambetti P, Kong Q, Zou W, Parchi P, Chen SG: Sporadic and familial CJD: classification and characterisation. Br Med Bull 2003, 66:213-239.

3. Goldgaber D, Goldfarb LG, Brown P, et al: Mutations in familial Creutzfeldt-Jakob disease and Gerstmann-Straussler-Scheinker's syndrome. Exp Neurol 1989, 106:204-206.

4. Lee HS, Sambuughin N, Cervenakova L, et al: Ancestral origins and worldwide distribution of the PRNP 200K mutation causing familial Creutzfeldt-Jakob disease. Am J Hum Genet 1999, 64:1063-1070.

5. Korczyn AD, Chapman J, Goldfarb LG, Brown P, Gajdusek DC: A mutation in the prion protein gene in Creutzfeldt-Jakob disease in Jewish patients of Libyan, Greek, and Tunisian origin. Ann N Y Acad Sci 1991, 640:171-176.

6. Kovacs GG, Puopolo M, Ladogana A, et al: Genetic prion disease: the EUROCJD experience. Hum Genet 2005, 118:166-174.

7. Kovacs GG, Trabattoni G, Hainfellner JA, Ironside JW, Knight RS, Budka H: Mutations of the prion protein gene phenotypic spectrum. J Neurol 2002, 249:1567-1582.

8. Mitrova E, Belay G: Creutzfeldt-Jakob disease with E200K mutation in Slovakia: characterization and development. Acta Virol 2002, 46:31-39.

9. Hsiao K, Meiner Z, Kahana E, et al: Mutation of the prion protein in Libyan Jews with Creutzfeldt-Jakob disease. N Engl J Med 1991, 324:1091-1097.

10. Meiner Z, Gabizon R, Prusiner SB: Familial Creutzfeldt-Jakob disease. Codon 200 prion disease in Libyan Jews. Medicine (Baltimore) 1997, 76:227-237.

11. Ghetti B, Piccardo P, Spillantini MG, et al: Vascular variant of prion protein cerebral amyloidosis with tau-positive neurofibrillary tangles: the phenotype of the stop codon 145 mutation in PRNP. Proc Natl Acad Sci USA 1996, 93:744-748.

12. Debatin L, Streffer J, Geissen M, Matschke J, Aguzzi A, Glatzel M: Association between deposition of beta-amyloid and pathological prion protein in 
sporadic Creutzfeldt-Jakob disease. Neurodegener Dis 2008, 5:347-354. doi: $10.1159 / 000121389$.

13. Ghoshal N, Cali I, Perrin RJ, et al: Codistribution of amyloid beta plaques and spongiform degeneration in familial Creutzfeldt-Jakob disease with the E200K-129M haplotype. Arch Neurol 2009, 66:1240-1246.

14. Kovacs GG, Seguin J, I Q, et al: Genetic Creutzfeldt-Jakob disease associated with the E200K mutation: characterization of a complex proteinopathy. Acta Neuropathol 2011, 121:39-57. doi: 10.1007/s00401-010-0713-y.

15. Vital A, Fernagut $\mathrm{PO}$, Canron $\mathrm{MH}$, et al: The nigrostriatal pathway in Creutzfeldt-Jakob disease. J Neuropathol Exp Neurol 2009, 68:809-815. doi: 10.1097/NEN.0b013e3181abdae8,

16. Carswell C, Thompson A, A L, et al: MRI findings are often missed in the diagnosis of Creutzfeldt-Jakob disease. BMC Neurol 2012, 12:153. doi: $10.1186 / 1471-2377-12-153$.

17. Puoti G, Rossi G, G G, et al: Polymorphism at codon 129 of PRNP affects the phenotypic expression of Creutzfeldt-Jakob disease linked to E200K mutation. Ann Neurol 2000, 48:269-270

18. Geschwind MD, Potter CA, Sattavat M, et al: Correlating DWI MRI with pathologic and other features of Jakob-Creutzfeldt disease. Alzheimer Dis Assoc Disord 2009, 23:82-87.

19. Safar JG, Geschwind MD, Deering C, et al: Diagnosis of human prion disease. Proc Natl Acad Sci USA 2005, 102:3501-3506.

20. Kretzschmar HA, Ironside JW, DeArmond SJ, Tateishi J: Diagnostic criteria for sporadic Creutzfeldt-Jakob disease. Arch Neurol 1996, 53:913-920.

21. Gundersen HJ, Jensen EB, Kieu K, Nielsen J: The efficiency of systematic sampling in stereology-reconsidered. J Microsc 1999, 193:199-211.

22. Parchi P, Giese A, Capellari S, et al: Classification of sporadic Creutzfeldt-Jakob disease based on molecular and phenotypic analysis of 300 subjects. Ann Neurol 1999, 46:224-233.

23. Cali I, Castellani R, J Y, et al: Classification of sporadic Creutzfeldt-Jakob disease revisited. Brain 2006, 129:2266-2277.

24. Kascsak RJ, Rubenstein R, Merz PA, et al: Mouse polyclonal and monoclonal antibody to scrapie-associated fibril proteins. J Virol 1987, 61:3688-3693.

25. Tartaglia MC, Sidhu M, V L, et al: Sporadic corticobasal syndrome due to FTLD-TDP. Acta Neuropathol 2010, 119:365-374. doi: 10.1007/s00401-009-0605-1.

26. Kovacs GG, Molnar K, Keller E, Botond G, Budka H, Laszlo L: Intraneuronal immunoreactivity for the prion protein distinguishes a subset of E200K genetic from sporadic Creutzfeldt-Jakob Disease. J Neuropathol Exp Neurol 2012, 71:223-232. doi: 10.1097/NEN.0b013e318248aa70.

27. Monari $L$, Chen SG, P B, et al: Fatal familial insomnia and familial Creutzfeldt-Jakob disease: different prion proteins determined by a DNA polymorphism. Proc Natl Acad Sci USA 1994, 91:2839-2842.

28. Parchi P, Capellari S, Chen SG: Typing prion isoforms. Nature 1997, 386:232-234.

29. Hainfellner JA, Parchi P, Kitamoto T, Jarius C, Gambetti P, Budka H: A novel phenotype in familial Creutzfeldt-Jakob disease: prion protein gene E200K mutation coupled with valine at codon 129 and type 2 protease-resistant prion protein. Ann Neurol 1999, 45:812-816.

30. Geschwind MD, Kuryan C, Cattaruzza T, Vitali P, DeArmond S, Wong K: Brain MRI in sporadic Jakob-Creutzfeldt disease is often misread. Neurology 2010, 78:P03.018.

31. Appel SA, Chapman J, Prohovnik I, Hoffman C, Cohen OS, Blatt I: The EEG in E200K familial CJD: relation to MRI patterns. J Neurol 2012, 259:491-496. doi: 10.1007/s00415-011-6208-5.

32. Fulbright RK, Hoffmann C, Lee H, Pozamantir A, Chapman J, Prohovnik I: MR imaging of familial Creutzfeldt-Jakob disease: a blinded and controlled study. AJNR Am J Neuroradiol 2008, 29:1638-1643.

33. Brown P, Goldfarb LG, Gibbs CJ Jr, Gajdusek DC: The phenotypic expression of different mutations in transmissible familial Creutzfeldt-Jakob disease. Eur J Epidemiol 1991, 7:469-476.

34. Brown P, Cathala F, Castaigne P, Gajdusek DC: Creutzfeldt-Jakob disease: clinical analysis of a consecutive series of 230 neuropathologically verified cases. Ann Neurol 1986, 20:597-602.

35. Jarius C, Kovacs GG, Belay G, Hainfellner JA, Mitrova E, Budka H: Distinctive cerebellar immunoreactivity for the prion protein in familial (E200K) Creutzfeldt-Jakob disease. Acta Neuropathol 2003, 105:449-454. doi: $10.1007 /$ s00401-002-0664-z

36. Capellari S, Strammiello R, Saverioni D, Kretzschmar H, Parchi P: Genetic Creutzfeldt-Jakob disease and fatal familial insomnia: insights into phenotypic variability and disease pathogenesis. Acta Neuropathol 2011, 121:21-37.
37. Taratuto AL, Piccardo P, Reich EG: Insomnia associated with thalamic involvement in E200K Creutzfeldt-Jakob disease. Neurology 2002, 58:362-367.

38. Medori $\mathrm{R}$, Tritschler HJ, A LB, et al: Fatal familial insomnia, a prion disease with a mutation at codon 178 of the prion protein gene. N Engl J Med 1992, 326:444-449. doi: 10.1056/NEJM199202133260704.

39. Parchi P, Capellari S, S C, et al: A subtype of sporadic prion disease mimicking fatal familial insomnia. Neurology 1999, 52:1757-1763.

40. Elobeid $\mathrm{A}$, Soininen $\mathrm{H}$, Alafuzoff I: Hyperphosphorylated tau in young and middle-aged subjects. Acta Neuropathol 2012, 123:97-104. doi: 10.1007/ s00401-011-0906-Z

41. Kitamoto T, Shin RW, K D-u: Abnormal isoform of prion proteins accumulates in the synaptic structures of the central nervous system in patients with Creutzfeldt-Jakob disease. Am J Pathol 1992, 140:1285-1294.

42. Fraser $\mathrm{H}$ : Neuronal spread of scrapie agent and targeting of lesions within the retino-tectal pathway. Nature 1982, 295:149-150.

43. Scott JR, Davies D, Fraser H: Scrapie in the central nervous system: neuroanatomical spread of infection and Sinc control of pathogenesis. J Gen Virol 1992, 73(Pt 7):1637-1644.

44. Beekes M, McBride PA, Baldauf E: Cerebral targeting indicates vagal spread of infection in hamsters fed with scrapie. J Gen Virol 1998, 79(Pt 3):601-607.

45. Bouzamondo-Bernstein E, Hopkins SD, P S, et al: The neurodegeneration sequence in prion diseases: evidence from functional, morphological and ultrastructural studies of the GABAergic system. J Neuropathol Exp Neurol 2004, 63:882-899.

46. Gardner RC, Boxer AL, A T, et al: Intrinsic connectivity network disruption in progressive supranuclear palsy. Ann Neurol 2013. doi: 10.1002/ana.23844.

47. Frost B, Ollesch J, Wille H, Diamond Ml: Conformational diversity of wild-type Tau fibrils specified by templated conformation change. J Biol Chem 2009, 284:3546-3551.

48. Frost B, Jacks RL, Diamond MI: Propagation of tau misfolding from the outside to the inside of a cell. J Biol Chem 2009, 284:12845-12852.

49. Kfoury N, Holmes BB, Jiang H, Holtzman DM, Diamond MI: Trans-cellular propagation of Tau aggregation by fibrillar species. J Biol Chem 2012, 287:19440-19451. doi: 10.1074/jbc.M112.346072.

50. Friedman-Levi Y, Meiner Z, Canello T, et al: Fatal prion disease in a mouse model of genetic E200K Creutzfeldt-Jakob disease. PLoS Pathog 2011, 7:e1002350. doi: 10.1371/journal.ppat.1002350 PPATHOGENS-D-11-01077.

doi:10.1186/2051-5960-1-80

Cite this article as: Kim et al:: Genetic CJD with a novel E200G mutation in the prion protein gene and comparison with E200K mutation cases. Acta Neuropathologica Communications 2013 1:80.

\section{Submit your next manuscript to BioMed Central and take full advantage of:}

- Convenient online submission

- Thorough peer review

- No space constraints or color figure charges

- Immediate publication on acceptance

- Inclusion in PubMed, CAS, Scopus and Google Scholar

- Research which is freely available for redistribution 